\title{
Chemometric assessment of soil organic matter storage and quality from humic acid infrared spectra
}

Marco A. Jiménez-González a, b, *, Ana M. Álvarez b , Pilar Carral b, Gonzalo Almendros $^{a}$

${ }^{a}$ Museo Nacional de Ciencias Naturales (MNCN-CSIC), c/Serrano 115-B, 28006 Madrid, Spain.

b Universidad Autónoma de Madrid (UAM), c/Francisco Tomás y Valiente 7, 28049 Madrid, Spain.

*email: majimenez@mncn.csic.es

Keywords: Carbon sequestration; Humic substances; Optical density; Partial least squares regression; Humus quality; Nuclear magnetic resonance

\section{Highlights}

- Lignin structures are major constituents of humic acids from soils of high $\mathrm{C}$ levels

- Humic acids from C-depleted soils are rich in aromatic and carboxyl groups

- Humic acid structure preserves information on soil properties as its $C$ content 


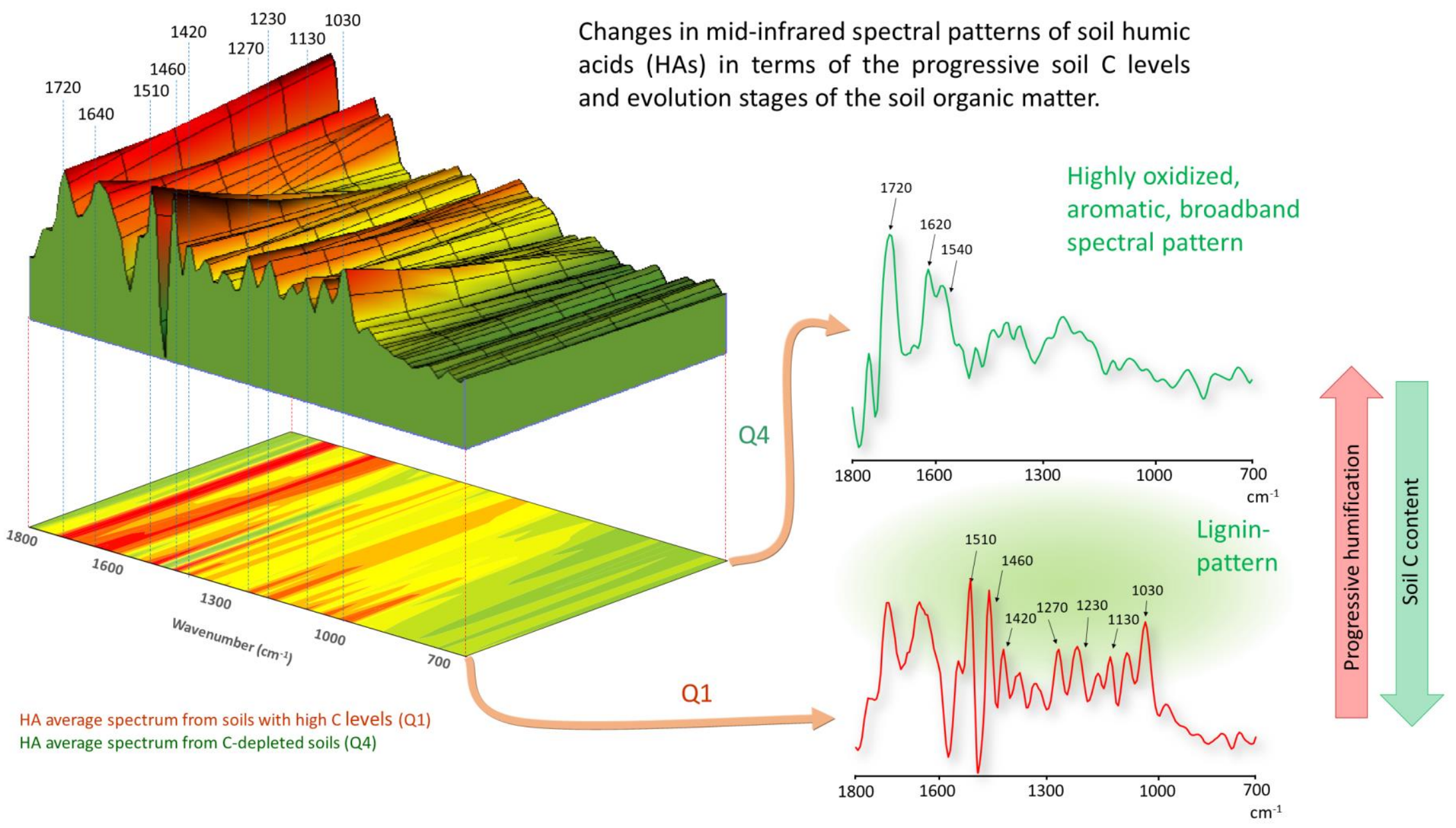




\section{Abstract}

The knowledge of biogeochemical mechanisms involved in soil organic carbon (SOC) storage is crucial to control its release to the atmosphere. In particular, the chemical composition of soil organic matter (SOM) plays an important role in the performance of the $\mathrm{C}$ storage and resilience in soils. The structural information provided by infrared spectroscopy (IR) of soil humic acid (HA) was used in the assessment of the $C$ storage potential of 35 Spanish soils. Partial least squares (PLS) regression using the intensities of the points of the IR spectra of the HAs $\left(4000-400 \mathrm{~cm}^{-1}\right)$ as descriptors shows that a relationship exists between IR spectral pattern and the SOC content. This was also the case for E4 (humification index based on HA optical density at $465 \mathrm{~nm}$ ). In addition, the chemical characteristics of the HAs correlated with the SOC levels were identified from digital data treatments of the IR spectra. Additional application of principal component analysis (PCA) and multidimensional scaling (MDS) suggested that bands assigned to carboxyl and amide structures were characteristic in HAs from soils with low $\mathrm{C}$ content, whereas HA spectra from soils with high $C$ levels showed a conspicuous band pattern suggesting structural units of lignin from slightly transformed plant residues. The spectral profiles were analyzed in detail by an approach based on digital subtraction of IR spectra obtained by averaging those from HAs extracted from soils in the upper and lower quartiles of the SOC distribution. The results showed that significant relationships exist between the molecular composition of HAs and $\mathrm{SOC}$ levels and E4 values in a way in which aromatic, carboxyl and amide groups were predominant in HAs from soils with low SOC content, whereas lignin-derived structures were more characteristic of HAs from soils with high SOC content.

\section{Introduction}

Global change presumptively produced by increasing carbon dioxide $\left(\mathrm{CO}_{2}\right)$ emission to the atmosphere is a well-publicized subject of research from different scientific fields. In fact, soil represent one of the major $C$ reservoirs at the Earth's level (Batjes, 1996; Lal, 2004), then the study of the dynamics of the soil organic carbon (SOC) and the optimization of soil management practices is interesting in terms of preventing increased emissions of $\mathrm{CO}_{2}$ from soil (Pizzeghello et al. 2017; 
Hernández et al. 2019). In fact, even a small variation in the SOC pool may be reflected in the resulting atmospheric $\mathrm{CO}_{2}$ concentration (Lal, 2004).

Biogeochemical factors responsible for SOC storage are only partially known: the stabilization of soil organic matter (SOM) by organo-mineral complexation, or physical protection including microencapsulation plays an important role in enhancing SOC sequestration (Spaccini et al. 2002; Spaccini and Piccolo, 2012; Simonetti et al. 2017). On the other hand, stabilization mechanisms depending on the chemical composition of the SOM are also very important (Solomon et al., 2007; JiménezGonzález et al. 2017; 2018). In fact, SOM chemical composition depends on a plethora of biochemical and abiotic reactions such as the occasional but relevant influence of wildfires (Jiménez-González et al., 2016; Pereira et al., 2016). Most research on SOM has progressed significantly taking advantage of studies on the operationally defined humic substances (Spaccini et al., 2002; Song et al., 2014). Such humic substances can be divided into three fractions: fulvic acids (alkali- and acid-soluble fraction), humic acids (HAs) (alkali-soluble and acid-insoluble) and humin (alkali- and acid- insoluble). In particular the HA fraction, which represent one of the most structurally complex pools of the SOM, has been the subject of extensive research on its composition, reactions and hypothetical structural models (Schnitzer and Khan, 1972; Hayes et al., 1989; Hayes, 1991; Stevenson, 1994; Piccolo, 2002, Piccolo et al., 2018). In fact, recent studies take advantage of the classical idea that research on the molecular structure of humic substances represents a source of still unexplored information about biogeochemical processes (Baveye and Wander, 2019). The transformation of SOM and in particular the HA formation pathways depend on different environmental factors (Parton et al., 1987) and are expressed by means of progressive changes in the macromolecular structure of the SOM (Stevenson, 1994). In fact, the molecular composition of the HAs differs from that of the precursor plant- or microorganism-derived biomass (Miller et al., 2015; Tadini et al., 2015) and the extent of such structural differences as regards biomass could be postulated as a valid surrogate of the SOM maturity, humification degree, or SOM quality (Almendros et al., 2018; Jiménez-González et al., 2018).

Using non-destructive techniques such as infrared (IR) spectroscopy and solidstate nuclear magnetic resonance $\left(\mathrm{NMR}{ }^{13} \mathrm{C}\right)$ it is possible to perform an exploratory analysis of soil characteristics associated with the specific HA chemical composition. 
Current studies have used mid-IR spectra to predict soil properties (Madari et al., 2006; Janik et al., 2007; D’Acqui et al., 2010; Cécillon et al., 2012), or to study dissolved organic matter in aquatic ecosystems (Abdulla et al., 2010). Typical bands of IR spectra have been systematically ascribed to different SOM chemical constituents and used as valuable semiquantitative descriptors of the impact of several types of environmental factors on SOM characteristics (MacCarthy and Rice, 1985; Fernández-Getino et al., 2013; Miralles et al., 2015) i.e., 1720, $1620 \mathrm{~cm}^{-1}$, associated to carboxyl and aromatic groups, $2920,1460 \mathrm{~cm}^{-1}$ bands for alkyl structures, $1650,1640 \mathrm{~cm}^{-1}$ bands related with protein, or 1510, 1460, 1270, 1230, $1130,1030 \mathrm{~cm}^{-1}$ coinciding with typical lignin structural units (Fengel and Wegener, 1984; Yang et al., 2011). Using the intensity of the above bands combined with quantitative integration data of the different regions of the NMR ${ }^{13} \mathrm{C}$ spectra of the HAs, it is possible obtain a reliable insight of the variability in the HAs' chemical constituents. Nevertheless, in the case of IR spectroscopy, further refinement based on spectral data treatments such as obtaining derivative spectra, autodeconvolution, or resolution enhancement (Almendros et al., 1992) can be very helpful for quantitative assessments, exploratory spectral pattern recognition or to improve the significance levels of chemometric models to relate spectroscopic data with different soil properties as could be SOC content or SOM quality. Although some of these treatments modify IR peak intensities, this effect is the same for homologous peaks of spectra processed by the same procedure. In particular, second derivative IR spectra are usually chosen due to it allow accurate measurement of peak intensities (Luinge et al., 1995; Viscarra Rosell, 2008).

This research includes the application of partial least squares (PLS) regression to explore soil properties reflected in the mid-IR pattern $\left(4000-400 \mathrm{~cm}^{-1}\right)$ of soil HAs. The principal goal is to explore if there is a relationship between both the SOC content and E4 index, and the IR spectral signature of HAs isolated from the corresponding soils. In a second stage, this research aims to differentiate any specific spectroscopic pattern of HAs accumulated in soils with high potential for SOC storage, with that of HAs from $\mathrm{C}$ depleted soils. 


\section{Materials and methods}

\subsection{Study area}

Thirty-five topsoil samples $(0-10 \mathrm{~cm})$ were collected from different Spanish ecosystems developed under widely differing environmental characteristics. The general characteristics of soil sampling areas were reported elsewhere (JiménezGonzález et al., 2017; 2018). The soils were selected intending to cover a wide range

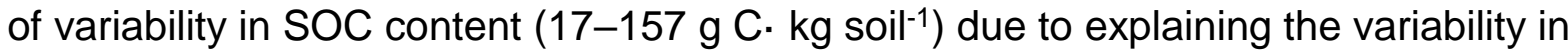
this soil property is a main objective of this work. Three sampling points were selected for each soil area, the samples were collected from the A horizon after removing the litter layer. Finally, composite soil samples were prepared by mixing soil subsamples from three different points, and the resulting materials were air-dried at room temperature for a week and homogenized to $<2 \mathrm{~mm}$.

\subsection{Soil physical and chemical analysis}

The soils were classified according to the World Reference Base for Soil Resources (2014) system. Soil texture was determined by the densimeter method (Bouyoucos, 1927). Soil pH was measured in soil-water suspension (1:2.5, w:w) with a $\mathrm{pH} 7 \mathrm{pH}$-meter (XS Instruments; Carpi, MO, Italy). The electrical conductivity (EC) was determined with a COND7 conductivity-meter (XS instruments; Carpi MO, Italy) using soil-water slurry (1:5, w:w). The SOC concentration was determined by wet chemical oxidation with $1 \mathrm{M}$ potassium dichromate (Nelson and Sommers, 1982; Walkley and Black, 1934), and the nitrogen ( $N$ ) by micro-Kjeldahl digestion (Nelson and Sommers, 1982). The water holding capacity (WHC) of the soils was measured in the laboratory at atmospheric pressure. Table 1 shows some properties of the soils and its corresponding HAs. Additional physical and chemical properties (EC, WHC, $\mathrm{pH}$, soil texture, bulk density) were reported elsewhere (Jiménez-González et al., 2017 ; 2018) 


\subsection{Isolation and characterization of humic acids}

The first step of the SOM fractionation consisted of removing free organic matter (FOM, particulate SOM fraction) by flotation in $2 \mathrm{M} \mathrm{H}_{3} \mathrm{PO}_{4}$. The humic extract was extracted with $0.1 \mathrm{M} \mathrm{Na}_{4} \mathrm{P}_{2} \mathrm{O}_{7}$ and $0.1 \mathrm{M} \mathrm{NaOH}$ in reducing atmosphere. The HAs were separated from fulvic acids (FAs) by precipitating the humic extract with $6 \mathrm{M}$ $\mathrm{HCl}$. The HAs were purified by high-speed centrifugation $(46,000 \times \mathrm{g})$ followed by dialysis (Visking tube size 6, Medicell International Ltd.) to remove soluble salts.

The optical density (E4) of the HAs was determined at $465 \mathrm{~nm}$ in HA solutions in $0.01 \mathrm{M} \mathrm{NaOH}$ at a concentration of $0.2 \mathrm{mg} \cdot \mathrm{cm}^{-3}$ (Kononova, 1982), this index is related with the humification degree and has been considered a reliable surrogate of the aromaticity of HAs (Traina et al., 1990; Tinoco et al., 2014).

The main HA structural groups were quantified using solid-state ${ }^{13} \mathrm{C} N M R$ spectroscopy using a Bruker Avance $400 \mathrm{MHz}$ instrument, operating at a frequency of $100.63 \mathrm{MHz}$ with $4 \mathrm{~mm}$ o.d. zirconium oxide rotors with Kel-F caps. The cross polarization (CP) was used during magic-angle spinning (MAS) of the rotor at 12.5 $\mathrm{kHz}$. Between 5000 and 6000 scans were accumulated with a pulse delay of $300 \mathrm{~ms}$. Tetramethylsilane was used to calibrate the ${ }^{13} \mathrm{C}$ chemical shifts $(0 \mathrm{ppm})$. To circumvent Hartmann-Hahn mismatches, a ramped $1 \mathrm{H}$-pulse was applied during the $1 \mathrm{~ms}$ contact time. The spectral ranges were described according to the body of classical literature (González-Vila et al., 1983; Knicker, 2011): Alkyl + a-amino C (045 ppm); N-alkyl + $\mathrm{OCH}_{3} \mathrm{C}$ (45-60 ppm); O-alkyl C (60-110 ppm); unsubstituted aromatic C (110-140 ppm); heteroaromatic C (140-160); carbonyl C (mainly carboxyl + amide, 160-220 ppm). In this study, special attention was paid to the unsubstituted aromatic $\mathrm{C}$ region (110-140 ppm). The ${ }^{13} \mathrm{C}$ intensity distribution was determined by integrating peak areas over the above-mentioned chemical shift regions.

\subsection{Infrared spectroscopy}

Fourier transform-infrared spectra were acquired with a Cary 630 FTIR spectrophotometer at a wavelength range of $4000-400 \mathrm{~cm}^{-1}$ and a resolution of 4 $\mathrm{cm}^{-1}$. Potassium bromide $(\mathrm{KBr})$ pellets containing $2 \mathrm{mg}$ of powdered $\mathrm{HA}$ and $200 \mathrm{mg}$ 
of $\mathrm{KBr}$ were scanned. Spectral data were background corrected to a reference spectrum prior to every measurement and some spurious bands, such as those from atmospheric $\mathrm{CO}_{2}$ were removed. Resolution enhancement techniques (Almendros et al., 1992) are very useful in case of typical broadband IR spectra such as those from HAs, these spectral data treatments revealed peaks not evident in the original spectra. The method used is based on subtracting from the raw spectrum a positive multiple of its $2^{\text {nd }}$ derivative (Fig. 1 ). Finally, $2^{\text {nd }}$ derivative spectra, which show a systematic pattern of peaks and valleys and a straight virtual baseline, were chosen for semi-quantitative measurement of peak intensities (Fernández-Getino et al., 2013).

\subsection{Statistical analysis}

Partial least squares regression using the ParLeS software (Viscarra Rossel, 2008) was used to explain the variance of the SOC content (as dependent variable) in terms of a large series of descriptors (independent variables) consisting of the spectral points $\left(4000-400 \mathrm{~cm}^{-1}\right)$ after mean centering. The $2^{\text {nd }}$ derivative transformation of the IR spectra was selected amongst a series of standard preprocessing and pretreatment algorithms included in the program for model optimization. The PLS was applied to explore the possible relationship between the IR spectrum and SOC and E4 values, the fact that a model is possible shows that a relationship exists between them. The root mean squared error (RMSE) and the Akaike's information criterion (AIC) (Akaike, 1974) were used to select PLS models with the minimum number of factors or latent variables (LVs) i.e., to prevent overfitted spurious models. Then, the results were shown in a cross-validation plot.

In a second stage, and in order to identify spectral features characteristic of the IR spectra of HAs from soils with different SOC levels, the spectra were ordered according the $\mathrm{C}$ content of the corresponding soils and two subsets were considered for comparison, i.e., soils above vs. below the median of the $C$ levels, or "soils behaving as C-sinks" vs. "soils with low SOC levels". Finally, samples were classified by quartiles (Q1 to Q4), after observing that the differences were the same but more important in the case of quartiles. The average of the IR spectra from the HAs of soils in the 1st quartile (Q1, samples with highest SOC content) and the average spectra 
of IR from the HAs from soils with C levels in the 4th quartile (Q4, samples with lowest SOC content) were calculated. The subtraction of the average spectra from HA samples of these quartiles was carried out to recognize the characteristics spectral bands prevailing in each subset. A similar process was carried out using the E4: the spectra were ordered according the value of E4 of the HAs, and then IR intensity values of average spectra of samples in Q1 and Q4 were subtracted.

In addition, and in an attempt to obtain more perceptual plots illustrating the spectral features of HAs from soils classified according to SOC or E4 values two independent spectral traces, respectively highlighting the positive or negative intensities in the above subtracted spectra were obtained. For this purpose, the average spectrum from samples in Q1 is multiplied by a factor suitable to make equal to zero the difference value at the most intense valley in the subtracted spectrum: then the resulting subtracted array (Q1-Q4) exclusively contains positive values, i.e., a virtual spectrum consisting of the characteristic bands prevailing in HA samples from the Q1 set (Manders, 1987; Martínez et al., 1990). The same operation was carried out to obtain the spectrum emphasizing the bands prevailing in HAs from soils with low SOC content, corresponding to the negative subtraction values. In this case the data array in Q1 spectrum was multiplied by a factor to obtain a spectral array where the highest value in the subtracted spectrum would coincide with the zero value, consequently all peaks in the subtraction are negative. Finally, the resulting array was multiplied by -1 to plot a positive trace. The Student $t$ test was calculated for each spectral point to illustrate the significance level $(P<0.05)$ of the spectral intensities of sample sets with different SOC levels.

The relationships between the SOC content and other soil and HA properties were examined by principal component analysis (PCA, correlation matrix, no rotation) using as variables the normalized intensities of the principal IR bands measured in the $2^{\text {nd }}$ derivative and the Statistica ver. 7.1 software. This multivariate data treatment was used aiming to independently check the different contributions of individual IR bands to the variability of $\mathrm{SOC}$ and $\mathrm{E} 4$. These properties were processed as supplementary variables, i.e., those which are not used to calculate the ordination axes. The principal components were calculated using only the intensity of the selected IR bands as principal variables. Supplementary variables are represented in 
the space according to the components calculated from the principal variables (Legendre and Legendre 1998).

Finally, multidimensional scaling (MDS, Kruskal, 1964) was applied to study mutual relationships between the intensity of the main IR spectral bands and soil variables, using the 1-Pearson $r$ correlation index as a measure of similarity. Therefore, the proximity of the scores so calculated for the variables in the plane is considered proportional to their mutual correlations.

\section{Results}

\section{1. ${ }^{13} \mathrm{C}$ NMR spectra}

The high variability in the chemical composition of the HAs was suggested by the solid-state ${ }^{13} \mathrm{C}$ NMR spectra. The $0-45$ ppm range, associated to alkyl C, was a major region of the ${ }^{13} \mathrm{C}$ NMR spectra, accounting for 25.5 to $41.5 \%$. The signal intensity corresponding to the $45-60$ ppm region $\left(\mathrm{N}\right.$-alkyl $\left.+\mathrm{OCH}_{3}\right)$ showed low variation (7.9 to $11.8 \%$ ). The lowest intensity in the $60-110$ ppm region (O-alkyl C) was $14.3 \%$ and the highest value reached $27.4 \%$. The $110-140 \mathrm{ppm}$ region, corresponding to unsubstituted aromatic carbons showed values from 11.9 to $27.6 \%$ whereas the 140-160 ppm region for heteroaromatic carbons ranged between 4.3 and $7.4 \%$. Finally, the carbonyl region, between 160 and 220 ppm showed values ranging from 9.4 to $14.8 \%$.

\subsection{Partial least squares regression}

Figure 2 shows the leave-one-out cross-validation plots for the PLS prediction model obtained for SOC (i.e., SOM quantity) and E4 (i.e., SOM quality). In the best model selected, the values of RMSE and AIC suggested including up to 6 LVs in the model for SOC prediction and 2 LVs for E4. In the cross validation plot for the PLS model using the SOC values there was a significant correlation between predicted and observed values, with $R^{2}=0.626$. In the case of $\mathrm{E} 4$ values, a higher correlation $\left(R^{2}=0.886\right)$ than for SOC was obtained between the experimental values and the values predicted by the model. 


\subsection{Infrared spectra}

The Fig. 3 shows the 35 spectra superimposed to the corresponding resolution enhanced IR spectra. These spectra are ordered according E4 values and then according the SOC content. It is observed how the spectra with marked lignin pattern are located in the area of high SOC and low E4, whereas HAs from soils with low $\mathrm{C}$ levels tend to show strong carboxyl and aromatic bands.

In Fig. 4a, a comprehensive representation of the differences between spectroscopic patterns of HAs from soils with high levels of SOC as regards those with low potential for SOC storage, i.e., exposed to more severe risks of desertification, was obtained by subtracting the two spectra obtained after averaging spectra corresponding to sample sets with high and low SOC, respectively. This representation of the differential spectral features of HAs from soils in Q1 vs Q4 shows positive and negative peaks: the positive values correspond to bands predominant in the IR spectra of HAs isolated from soils with high SOC content (Q1). In the latter case, it is observed the bands 1510, 1460, 1420, 1270, 1130 and 1030 $\mathrm{cm}^{-1}$. On the other side (Q4), other bands are predominant in HAs from soils with low SOC levels, i.e., bands at $1540 \mathrm{~cm}^{-1}$ which are related with amide groups, or 1720 $\mathrm{cm}^{-1}$ bands linked to $\mathrm{C}=\mathrm{O}$ groups.

In the representation of the spectral profiles in which the positive and negative values are respectively extracted after zero-correction baseline by multiplying by a linear factor, the different composition of the corresponding HAs (from C-rich and Cpoor soils) became much more evident. The first spectrum representing the positive region, showed the well-defined lignin pattern with sharp peaks (Fig. 4a). The second spectrum, which emphasizes the negative region of the subtraction spectrum, showed a prominent peak at $1720 \mathrm{~cm}^{-1}(\mathrm{C}=\mathrm{O}$ groups) and a broad band at 1620$1640 \mathrm{~cm}^{-1}$ (aromatic, unsaturated, quinone and amide structures). The same conclusion, but with opposite signs was obtained in the subtraction spectra obtained using the E4 ranks as classification factor (Fig. 4b). Negative values which are predominant in HAs with low E4 values define a spectrum with a marked lignin pattern whereas the spectrum displaying the positive values after the subtraction showed marked bands at 1720, 1620 and $1540 \mathrm{~cm}^{-1}$. 


\subsection{Principal component analysis}

The PCA results are shown as a biplot in Fig. 5. The two first components obtained using as variables the intensities of the principal bands of the IR spectra explained $27.4 \%$ (first component) and $19.5 \%$ (second component) of the total variance. Observing the position of the eigenvectors corresponding to the variables (band intensities of the IR spectra) used to calculate the components, it is possible to describe relationships existing between them according the location in the plane defined by the two components selected. The labels of the soil samples were located in the plane according the factors calculated. It is observed that eigenvectors for a set of bands $\left(1510,1460,1420,1370,1270,1130,1030 \mathrm{~cm}^{-1}\right)$ are oriented towards a common region of the factorial space. In the same area of these bands in the plot, other soil properties like SOC, WHC, C/N ratio are located closer. On the other hand, high loading factors for bands at 1720 and $1620 \mathrm{~cm}^{-1}$ are defined in the opposite region near to properties such as E4, and aromatic (110-140 ppm) and carbonyl C regions of the NMR spectra (160-220 ppm).

\subsection{Multidimensional scaling}

The scatterdiagram in Fig. 6 shows the ordination of the variables using MDS. The final stress level in this analysis was 0.225 (Kruskal, 1964). In general, MDS analysis confirms the mutual relationships between variables suggested by PCA. In this case, the scores for variables related with SOM quality as E4, aromaticity (110 $140 \mathrm{ppm}$ ) determined by NMR and intensity of the IR band at $1720 \mathrm{~cm}^{-1}$ are located closer with a significant correlation of $95 \%$ and in the opposite site to SOC level in the scatterplot. The SOC is located close to IR bands $1510,1270,1030 \mathrm{~cm}^{-1}$ and variables like $\mathrm{WHC}$ and Het-/H-Ar with a correlation of $95 \%$. In addition, a set of bands $\left(1460,1420,1370,1130 \mathrm{~cm}^{-1}\right)$ and $\mathrm{C} / \mathrm{N}$ are also clustering close to SOC in a correlation of $90 \%$. 


\section{Discussion}

The analysis by ${ }^{13} \mathrm{C}$ NMR spectroscopy showed clear differences in the chemical composition of the HAs. In particular, some ${ }^{13} \mathrm{C}$ NMR regions such as that for unsubstituted aromatic $C$ (110-140 ppm) showed large variability. The intensity of this region is often considered to parallel the degree of humification (Tinoco et al., 2014). This is due to the fact that constituents of plant and microbial biomass have a comparatively aliphatic character: both the microbial biomass and even lignin from vascular plants, have not such a high proportion of unsubstituted aromatic carbons. This result suggests great differences in the advanced stages in the humification process and could be useful to monitor the resulting maturity of the HAs.

The conspicuous prediction model obtained for SOC concentration exclusively using IR spectroscopic information indicated that a relationship exists between the functional groups of the HAs reflected in the IR spectra and the SOC level in the soils studied. Similar situation was found for E4, which was also predicted by a model exclusively using the IR spectral information. These findings suggest that the IR spectra of the HAs in the soils studied contain useful biogeochemical information about some soil characteristics such as SOC content, but also on qualitative HA properties on the transformation degree of the SOM, such as the E4, which is correlated with the proportions of carboxyl and aromatic structures (FernándezGetino et al., 2013; Miralles et al., 2015).

The arrangement of the IR spectra in Fig. 3 suggested the accumulation of ligninderived structures in the composition of $\mathrm{HAs}$ from soils with the higher $\mathrm{SOC}$ content and with low E4 values, whereas in soils with low SOC and high E4 this pattern is not observed. The subtraction (Fig. 4) between average IR spectra from soils belonging to quartiles in opposite levels of the SOC distribution (Q1-Q4) illustrates the predominant bands in the IR spectra according to the $\mathrm{C}$ storage potential of soils; the positive values (predominant bands in Q1) in the subtracted spectra reveal a characteristic IR lignin pattern viz., 1510, 1460, 1420, 1270, 1130 and $1030 \mathrm{~cm}^{-1}$ (Fengel and Wegener, 1984; Miralles et al., 2015). This would indicate that the soils under study with high SOC levels, display IR spectroscopic features of SOM in early transformation stages. On the other hand, negative values (predominant bands in Q4) of the subtracted spectra suggest a higher intensity of bands related with 
carboxyl groups $\left(1720 \mathrm{~cm}^{-1}\right)$ and amides $\left(1540 \mathrm{~cm}^{-1}\right)$. It is considered that these structures are characteristic of advanced humification or transformation stages (Stevenson, 1994; Jiménez-González et al., 2017; 2018; Tinoco et al., 2018). In fact, oxidized SOM with high aromaticity and $\mathrm{N}$ content would indicate extensive microbial reworking i.e., classically associated to an enhanced resilience of the resulting SOM (Requena et al., 1996; Almendros and Dorado, 1999; Pendall and King, 2007) driven by biogeochemical processes leading to progressively increased concentration of aromatic and carboxyl groups. This is better reflected in the two spectra illustratingafter multiplying by zero-baseline correction factors-the positive and negative peaks of the of Q1-Q4 spectral subtractions (Fig. 4). In the case of the E4 values, we found the opposite situation. Soils with high E4 not only display weak lignin pattern, but also intense $1720 \mathrm{~cm}^{-1}$ band, as well as prominent aromatic and amide regions (1620, $1540 \mathrm{~cm}^{-1}$ respectively), whereas soils with low E4 displayed well-defined IR peak lignin pattern. These facts suggest that SOM quantity and quality are linked to a different molecular composition. The HAs from soils with high SOC content tend to accumulate lignin and aliphatic structures suggesting the continuous input of fresh organic matter from vascular plants.

The biplot showing the arrangement of the studied samples and variables processed by PCA shows two groups of eigenvectors projected onto separate regions of the factorial space and presumably suggesting different $C$ storage processes. Thus, a group of eigenvectors points to the variable corresponding to the SOC concentration, whereas others point to the main processed SOM quality descriptor, E4. In addition, eigenvectors for bands corresponding to lignin structural units $\left(1510,1460,1420,1270,1230,1130 \mathrm{~cm}^{-1}\right)$ are grouped in the factorial space, as could correspond to the fact that these bands conform a conspicuous pattern in the IR spectra. The intensity of these bands, which are indicating comparatively slightly transformed SOM (Miralles et al., 2015), are correlated positively with the SOC levels. On the other hand, the projections of the eigenvectors associated to WHC and SOC were very similar, probably due to high SOC levels are connected to improved soil structure and water retention (Nath 2014; Libohova et al., 2018). The eigenvectors for $\mathrm{E} 4$, the intensity of the 110-140 ppm and 160-220 ppm of NMR region were oriented to the opposite side of the plot, coinciding with the scores for the samples in which the SOM evolution presumably reaches more advanced stages. 
In addition, the close relationship observed between these three variables and the intensities of the 1720 and $1620 \mathrm{~cm}^{-1} \mathrm{IR}$ bands indicate a high functionality expected from large concentration of aromatic and O-containing functional groups in HAs of high degree of maturity. This coincides with the fact that the eigenvector for $\mathrm{E} 4 \mathrm{a}$ classical index of the degree of transformation of HAs, points to similar zones than those for the unsubstituted aromatic and carbonyl region of NMR, the $1720 \mathrm{~cm}^{-1}$ carboxyl and the $1620 \mathrm{~cm}^{-1}$ aromatic IR bands. Such facts have been interpreted as the aromatic structures and reactive $O$-containing groups represent the final products of the humification process, represented by stable structures resistant to biodegradation (Stevenson, 1994). In consequence, the contrasted IR spectroscopic features recognized in the resolution-enhanced spectra suggest inverse relationship between quality and quantity of SOC in the studied soils, i.e., soils with low SOC content would contain HAs at comparatively advanced stages of transformation, whereas soils with high SOC levels would contain HAs comparatively richer in slightly transformed and labile structures. This fact also suggests that the routine treatments used for the extraction and purification of HAs are adequate to preserve relevant chemical information that can be recognized by IR spectroscopy and subsequently related to the origin and formation conditions of the SOM.

Finally, the MDS was useful to analyze the information about HA characteristics reflected in the IR spectra, viz, the close relationship between $E 4$, the intensity of the $1720 \mathrm{~cm}^{-1}$ band and the areas of the aromatic (110-140 ppm) and carbonyl (160-220 $\mathrm{ppm}){ }^{13} \mathrm{C}$ NMR regions, and the negative correlation of these variables with the SOC content that was located in the opposite side of the plane (Fig. 6). Such pattern of variables supports the suggestion that high SOC levels parallel accumulation of HAs with comparatively labile and slightly transformed biomass structures.

\section{Conclusions}

The analysis by IR spectroscopy of HAs from a set of Mediterranean soils formed under contrasting environmental factors suggests that the organic matter of soils with different $\mathrm{C}$ levels also have a different molecular composition. The methodological approach suggested, based on previous validation of PLS models to explain the soil C content using the IR spectra of HA as a source of descriptors, followed by digital 
subtraction between average spectra of HAs from soils with extreme values of $\mathrm{C}$, points out that the SOM levels paralleled the accumulation of HAs consisting of lignin-derived structures, whereas HAs in soils with low $\mathrm{C}$ levels present a composition in which aromatic, carbonyl and amide groups prevail. Concerning SOM quality or maturity (using E4 optical density of the HAs as comprehensive indicator) the results pointed to the opposite trend, i.e., the progressive depletion of lignin structures and accumulation of oxidized, aromatic, $\mathrm{N}$-containing structures. In any case, the resolution enhanced IR spectra behaved a reliable source of additional structural information on the impact of environmental processes involved in soil $\mathrm{C}$ storage which are reflected in the composition of the corresponding HA fraction.

\section{Acknowledgements}

The authors would like to thank Dr. Paulo Pereira, Associate Editor of Science of the Total Environment and two anonymous reviewers, who have greatly contributed to improve an early version of this paper. Financial support by the Spanish CICyT (grant CGL2013-43845-P) is gratefully acknowledged. Marco A. Jiménez-González thanks the Spanish Ministry of Economy and Competitiveness (MINECO) for funding his pre-doctoral FPI fellowship (BES-2014-069238).

\section{References}

Abdulla, H.A.N., Minor, E.C., Dias, R.F., Hatcher, P.H., 2010. Changes in the compound classes of dissolved organic matter along an estuarine transect: A study using FTIR and ${ }^{13} \mathrm{C}$ NMR. Geochim. Cosmochim. Acta 74, 3815-3838. https://doi.org/10.1016/j.gca.2010.04.006

Akaike, H., 1974. A new look at the statistical model identification. IEEE Trans. Automat. Contr. 19, 716-723. https://doi.org/10.1109/TAC.1974.1100705

Almendros, G., González-Vila, F.J, Martín, F., Fründ, R., Lüdemann, H.-D., 1992.

Solid state NMR studies of fire-induced changes in the structure of humic substances. Sci. Total Environ. 117-118, 63-74. https://doi.org/10.1016/0048$\underline{\text { 9697(92)90073-2 }}$ 
Almendros, G., Dorado, J.,1999. Molecular characteristics related to the biodegradability of humic acid preparations. Eur. J. Soil Sci. 50, 227-236. https://doi.org/10.1046/j.1365-2389.1999.00240.x

Almendros, G., Hernández, Z., Sanz, J., Rodríguez-Sánchez, S., Jiménez-González, M.A., González-Pérez, J.A., 2018. Graphical statistical approach to soil organic matter resilience using analytical pyrolysis data. J. Chromatogr. A 1533, 164-173. https://doi.org/10.1016/i.chroma.2017.12.015

Batjes, N.H., 1996. Total carbon and nitrogen in the soils of the world. Eur. J. Soil Sci. 47, 151-163. https://doi.org/10.1111//.1365-2389.1996.tb01386.x

Baveye, P.C., Wander, M., 2019. The (bio)chemistry of soil humus and humic substances: why is the "new view" still considered novel after more than 80 years? Front. Environ. Sci. 7, 27. https://doi.org/10.3389/fenvs.2019.00027.

Bouyoucos, G.J., 1927. The hydrometer as a new method for the mechanical analysis of soils. Soil Sci. 23, 343-353.

Cécillon, L., Certini, G., Lange, H., Forte, C., Strand, L.T., 2012. Spectral fingerprinting of soil organic matter composition. Org. Geochem. 46, 127-136. https://doi.org/10.1016/i.orggeochem.2012.02.006

D’Acqui, L.P., Pucci, A., Janik L.J., 2010. Soil properties prediction of western Mediterranean islands with similar climatic environments by means of mid-infrared diffuse reflectance spectroscopy. Eur. J. Soil Sci. 61, 865-876.

https://doi.org/10.1111/j.1365-2389.2010.01301.x

Fengel D., Wegener G., 1984. Wood: Chemistry, Ultrastructure, Reactions. Walter de Gruyter, Berlin and New York. 
Fernández-Getino, A.P., Hernández, Z., Piedra Buena, A., Almendros, G., 2013. Exploratory analysis of the structural variability of forest soil humic acids based on multivariate processing of infrared spectral data. Eur. J. Soil Sci. 64, 66-79. https://doi.org/10.1111/ejss.12016

González-Vila, F.J., Lüdemann, H-D., Martín, F., 1983. ${ }^{13}$ C-NMR structural features of soil humic acids and their methylated, hydrolyzed and extracted derivatives. Geoderma 31, 3-15. https://doi.org/10.1016/0016-7061(83)90080-0

Hayes, M.H.B., MacCarthy, P., Malcom, R.L., Swift, R.S., 1989. Humic Substances II: in Search of Structure. Wiley, New York.

Hayes, M.H.B., 1991. Advances in Soil Organic Matter Research: The Impact on Agriculture and the Environment. Woodhead Publishing, Sawston.

Hernández, Z., Almendros, A., Álvarez, A.M., Figueiredo, T., Carral, P., 2019. Soil carbon stabilization pathways as reflected by the pyrolytic signature of humic acid in agricultural volcanic soils. J. Anal. Appl. Pyrolysis 137, 14-28.

https://doi.org/10.1016/j.jaap.2018.10.015

Janik, L.J., Skjemstad, J.O., Shepherd, K.D., Spouncer L.R., 2007. The prediction of soil carbon fractions using mid-infrared-partial least square analysis. Aust. J. Soil Res. 45, 73-81. https://doi.org/10.1071/SR06083

Jiménez-González, M.A., De la Rosa, J.M., Jiménez-Morillo, N.T., Almendros G., González-Pérez, J.A., Knicker, H. 2016. Post-fire recovery of soil organic matter in a Cambisol from typical Mediterranean forest in Southwestern Spain. Sci. Total Environ. 572, 1414-1421. https://doi.org/10.1016/j.scitotenv.2016.02.134

Jiménez-González, M.A., Álvarez, A.M., Carral, P., González-Vila, F.J. Almendros G., 2017. The diversity of methoxyphenols released by pyrolysis-gas chromatography as predictor of soil carbon storage. J. Chromatogr. A 1508, 130137. https://doi.org/10.1016/j.chroma.2017.05.068 
Jiménez-González, M.A., Álvarez, A.M., Hernández, Z., Almendros, G., 2018. Soil carbon storage predicted from the diversity of pyrolytic alkanes. Biol. Fertil. Soils 54 , 617-629. https://doi.org/10.1007/s00374-018-1285-6

Knicker, H., 2011. Solid state CPMAS ${ }^{13} \mathrm{C}$ and ${ }^{15} \mathrm{~N}$ NMR spectroscopy in organic geochemistry and how spin dynamics can either aggravate or improve spectra interpretation. Org. Geochem. 42, 867-890.

https://doi.org/10.1016/j.orggeochem.2011.06.019

Kononova, M.M., 1982. Materia Orgánica del Suelo: su Naturaleza, Propiedades y Métodos de Investigación, Barcelona, Oikos Tau.

Kruskal, J.B., 1964. Multidimensional scaling by optimizing goodness of fit to a nonmetric hypothesis. Psychometrika 29, 1-27.

https://doi.org/10.1007/BF02289565

Lal, R., 2004. Soil carbon sequestration to mitigate climate change. Geoderma 123, 1-22. https://doi.org/10.1016/j.geoderma.2004.01.032

Legendre, P., Legendre, L., 1998. Numerical Ecology. Vol. 24, second ed. Elsevier Science.

Libohova, Z., Seyhold, C., Wysocki, D., Wills, S., Schoeneberger, P., Williams, C., Lindbo, D., Stott, D., Owens,P.R., 2018. Reevaluating the effects of soil organic matter and other properties on available water-holding capacity using the National Cooperative Soil Survey Characterization Database. J. Soil Water Conserv. 73, 411421. doi: 10.2489/jswc.73.4.411.

Luinge, H.J., van der Maas, J.H., Visser, T., 1995. Partial least squares regression as a multivariate tool for the interpretation of infrared spectra. Chemometr. Intell. Lab. Syst. 28, 129-138. https://doi.org/10.1016/0169-7439(95)80045-B 
MacCarthy, P., Rice, J.A., 1985. Spectroscopic methods (other than NMR) for determining functionality in humic substances. In: Aiken, G.R., McKnight, D.M., Wershaw, R.L., MacCarthy, P. (Eds.) Humic Substances in Soils, Sediments and Water, Wiley, New York, pp. 527-559.

Madari, B.E., Reeves III, J.B., Machado, P.L.O.A., Guimarães, C.M., Torres, E., McCarthy G.W., 2006. Mid- and near-infrared spectroscopic assessment of soil compositional parameters and structural indices in two Ferralsols. Geoderma 136, 245-259. https://doi.org/10.1016/i.geoderma.2006.03.026

Manders, W.F., 1987. Solid-state ${ }^{13} \mathrm{C}$ NMR determination of the syringyl/guaiacyl ratio in hardwoods. Holzforschung 41, 13-18.

https://doi.org/10.1515/hfsg.1987.41.1.13

Martínez, A.T., Barrasa, J.M., Almendros, G., González, A.E., 1990. Fungal transformation of lignocellulosics as revealed by chemical and ultrastructural analyses. In: Coughlan, M.P., Collaço M.T., (Eds.), Advances on Biological Treatments of Lignocellulosic Materials. Elsevier. London, pp. 129-147.

Miller, K.E., Lai, C.-T., Friedman, E.S., Angenent L.T., Lipson D.A., 2015. Methane suppression by iron and humic acids in soils of the Arctic Coastal Plain. Soil Biol. Biochem. 83, 176-183. https://doi.org/10.1016/j.soilbio.2015.01.022

Miralles, I., Piedra-Buena, A., Almendros, G., González-Vila, F.J., González-Pérez, J.A., 2015. Pyrolytic appraisal of the lignin signature in soil humic acids: Assessment of its usefulness as carbon sequestration marker. J. Anal. Appl. Pyrolysis 113, 107115. https://doi.org/10.1016/j.jaap.2014.11.010

Nath, T.N., 2014. Soil texture and total organic matter content and its influences on soil water holding capacity of some selected tea growing soils in Sivasagar district of Assam, India. Int. J. Chem. Sci. 12, 1419-1429. 
Nelson, D.V., Sommers, L.E,.1982. Total carbon, organic carbon and organic matter. In: Methods of Soil Analysis: Part 2, Chemical and Microbiological Properties, Second ed. Page, A. L., Miller, R.H., Keeney D.R. (Eds.), American Society of Agronomy, Madison, WI, pp 539-579.

Parton, W.J., Schimel, D.S., Cole C.V., Ojima, D.S., 1987. Analysis of factors controlling soil organic matter levels in Great Plains grasslands. Soil Sci. Soc. Am. J. 51, 1173-1179. https://doi.org/10.2136/sssaj1987.03615995005100050015x

Pereira, P., Rein, G., Martín, D., 2016. Past and present post-fire environments. Sci. Total Environ. 573, 1275-11277. https://doi.org/10.1016/j.scitotenv.2016.05.040

Pendall, E., King, J.Y., 2007. Soil organic matter dynamics in grassland soils under elevated $\mathrm{CO}_{2}$ : Insights from long-term incubations and stable isotopes. Soil Biol. Biochem. 39, 2628-2639. https://doi.org/10.1016/j.soilbio.2007.05.016

Piccolo, A., 2002. The supramolecular structure of humic substances: A novel understanding of humus chemistry and implications in soil science. Adv. Agron. 75, 57-134. https://doi.org/10.1016/S0065-2113(02)75003-7

Piccolo, A., Spaccini, R., Drosos, M., Vinci, G., Cozzolino, V., 2018. The molecular composition of humus carbon: recalcitrance and reactivity in soils, Garcia, C., Nannipieri, P., Hernandez, T. (Eds.), In: The Future of Soil Carbon. Academic Press pp. 87-124. https://doi.org/10.1016/B978-0-12-811687-6.00004-3

Pizzeghello, D., Francioso, O., Concheri, G., Muscolo, A., Nardi, S., 2017. Land use affects the soil $C$ sequestration in alpine environment, NE Italy. Forests 8, 197. https://doi.org/10.3390/f8060197

Requena, N., Azcón, M., Baca, M.T., 1996. Chemical changes in humic substances from compost due to incubation with ligno-cellulolytic microorganisms and effects on lettuce growth. Appl. Microbiol. Biotechnol. 45, 857-863. https://doi.org/10.1007/s002530050774 
Simonetti, G., Francioso, O., Dal Ferro, N., Nardi, S., Berti, A. Morari, F., 2017. Soil porosity in physically separated fractions and its role in SOC protection. J. Soils Sediments 17, 70-84. https://doi.org/10.1007/s11368-016-1508-0

Schnitzer, M., Khan, U.S., 1972. Humic Substances in the Environment. Dekker, New York.

Solomon, D., Lehmann, J., Thies, J., Schäfer, T., Liang, B., Kinyangi, J., Neves, E., Petersen, J., Luizão, F., Skjemstad, J., 2007. Molecular signature and sources of biochemical recalcitrance of organic C in Amazonian Dark Earths. Geochim. Cosmochim. Acta 71, 2285-2298. https://doi.org/10.1016/..gca.2007.02.014

Song, X-Y., Liu, S-T., Liu, Q-H., Zhang, W-J., Hu, C-G., 2014. Carbon sequestration in soil humic substances under long-term fertilization in a wheat-maize system from North China. J. Integr. Agric. 13, 562-569. https://doi.org/10.1016/S2095$\underline{3119(13) 60713-3}$

Spaccini, R., Piccolo, A., Conte, P., Haberhauer, G. Gerzabek, M.H., 2002. Increased soil organic carbon sequestration through hydrophobic protection by humic substances. Soil Biol. Biochem. 34, 1839-1851. https://doi.org/10.1016/S0038$\underline{0717(02) 00197-9}$

Spaccini, R., Piccolo, A., 2012. Carbon sequestration in soils by hydrophobic protection and In situ catalyzed photo-polymerization of soil organic matter (SOM): Chemical and physical-chemical aspects of SOM in field plots. In: Piccolo, A. (eds) Carbon Sequestration in Agricultural Soils. Springer, Berlin, Heidelberg. https://doi.org/10.1007/978-3-642-23385-2 4

Stevenson, F.J. 1994. Humus Chemistry: Genesis, Composition, Reactions. Wiley, New York. 
Tadini, A.M., Constantino, I.C., Nuzzo, A., Spaccini, R., Piccolo, A., Moreira, A.B., Bisinoti, M.C., 2015. Characterization of typical aquatic humic substances in areas of sugarcane cultivation in Brazil using tetramethylammonium hydroxide thermochemolysis. Sci. Total Environ. 518-519, 201-208.

https://doi.org/10.1016/j.scitotenv.2015.02.103

Tinoco, P., Almendros, G., González-Vila, F.J., Sanz, J., González-Pérez, J.A., 2014. Revisiting molecular characteristics responsive for the aromaticity of soil humic acids. J. Soils Sediments 15, 781-791. https://doi.org/10.1007/s11368-014-1033-y

Tinoco, P., Almendros, G., Sanz, J., 2018. Soil perturbation in Mediterranean ecosystems reflected by differences in free-lipid biomarker assemblages. J. Agric. Food Chem. 66, 9895-9906.

https://pubs.acs.org/action/showCitFormats?doi=10.1021\%2Facs.jafc. $8 \mathrm{~b} 01483$

Traina, S.J., Novak, J., Smeck, N.E., 1990. An ultraviolet absorbance method of estimating the percent aromatic carbon content of humic acids. J. Environ. Qual. 19, 151-153. doi:10.2134/jeq1990.00472425001900010023x

Viscarra Rossel, R.P., 2008. ParLeS: Software for chemometric analysis of spectroscopic data. Chemometr. Intell. Lab. Syst. 90, 72-83.

https://doi.org/10.1016/j.chemolab.2007.06.006

Walkley, A., Black, I.A., 1934. An examination of Degtjareff method for determining soil organic matter and a proposed modification of the chromic acid titration method. Soil Sci. 37, 29-37.

World Reference Base for Soil Resources 2014. International soil classification system for naming soils and creating legends for soil maps. World Soil Resources Reports No. 106. FAO, Rome. 
Yang, Q., Wu, S., Lou, R., LV, G. 2011. Structural characterization of lignin from wheat straw. Wood Sci. Technol. 45, 419-431. https://doi.org/10.1007/s00226-010$\underline{0339-1}$

Table 1 General characteristics of soil and humic acid samples

\begin{tabular}{|c|c|c|c|c|}
\hline Sample No. & $\mathrm{SOC}^{\mathrm{a}}\left(\mathrm{g} \cdot \mathrm{kg}^{-1}\right)$ & Soil C/N & $E 4^{b}(A U)$ & Het-/H-Arc \\
\hline 1 & 41 & 11.3 & 0.78 & 0.33 \\
\hline 2 & 67 & 14.8 & 1.14 & 0.30 \\
\hline 3 & 96 & 15.3 & 0.66 & 0.40 \\
\hline 4 & 87 & 13.3 & 0.38 & 0.37 \\
\hline 5 & 48 & 13.1 & 0.51 & 0.34 \\
\hline 6 & 17 & 13.9 & 1.29 & 0.26 \\
\hline 7 & 18 & 16.0 & 0.68 & 0.34 \\
\hline 8 & 87 & 13.3 & 0.86 & 0.35 \\
\hline 9 & 32 & 16.4 & 0.78 & 0.34 \\
\hline 10 & 140 & 18.1 & 0.71 & 0.39 \\
\hline 11 & 117 & 26.7 & 0.59 & 0.42 \\
\hline 12 & 93 & 8.9 & 0.53 & 0.40 \\
\hline 13 & 134 & 12.1 & 0.51 & 0.41 \\
\hline 14 & 104 & 18.5 & 0.61 & 0.45 \\
\hline 15 & 81 & 16.9 & 0.48 & 0.40 \\
\hline 16 & 55 & 18.0 & 0.55 & 0.40 \\
\hline 17 & 39 & 13.0 & 0.80 & 0.30 \\
\hline 18 & 105 & 17.0 & 0.51 & 0.40 \\
\hline 19 & 41 & 15.8 & 0.95 & 0.30 \\
\hline 20 & 44 & 13.4 & 0.61 & 0.36 \\
\hline 21 & 57 & 13.9 & 0.66 & 0.42 \\
\hline 22 & 27 & 17.0 & 0.95 & 0.30 \\
\hline 23 & 133 & 31.0 & 1.18 & 0.33 \\
\hline 24 & 90 & 20.0 & 0.76 & 0.38 \\
\hline 25 & 132 & 18.0 & 0.76 & 0.36 \\
\hline 26 & 18 & 22.0 & 1.60 & 0.27 \\
\hline 27 & 22 & 12.0 & 0.67 & 0.36 \\
\hline 28 & 23 & 14.0 & 0.72 & 0.36 \\
\hline 29 & 105 & 27.0 & 0.55 & 0.35 \\
\hline 30 & 35 & 20.0 & 0.66 & 0.32 \\
\hline 31 & 99 & 25.9 & 0.58 & 0.36 \\
\hline 32 & 46 & 16.8 & 1.13 & 0.35 \\
\hline 33 & 89 & 23.7 & 0.64 & 0.38 \\
\hline 34 & 157 & 21.6 & 0.46 & 0.38 \\
\hline 35 & 92 & 13.9 & 0.62 & 0.35 \\
\hline
\end{tabular}

aSOC: soil organic carbon ${ }^{\mathrm{b}} \mathrm{E} 4$ : optical density of humic acid solution $\left(0.2 \mathrm{mg} \cdot \mathrm{cm}^{-3}\right)$ at 465 $\mathrm{nm}{ }^{\mathrm{C}} \mathrm{Het}-/ \mathrm{H}-\mathrm{Ar}$ : ratio heteroaromatic/H-aromatic C (140-160 ppm/110-140 ppm). 


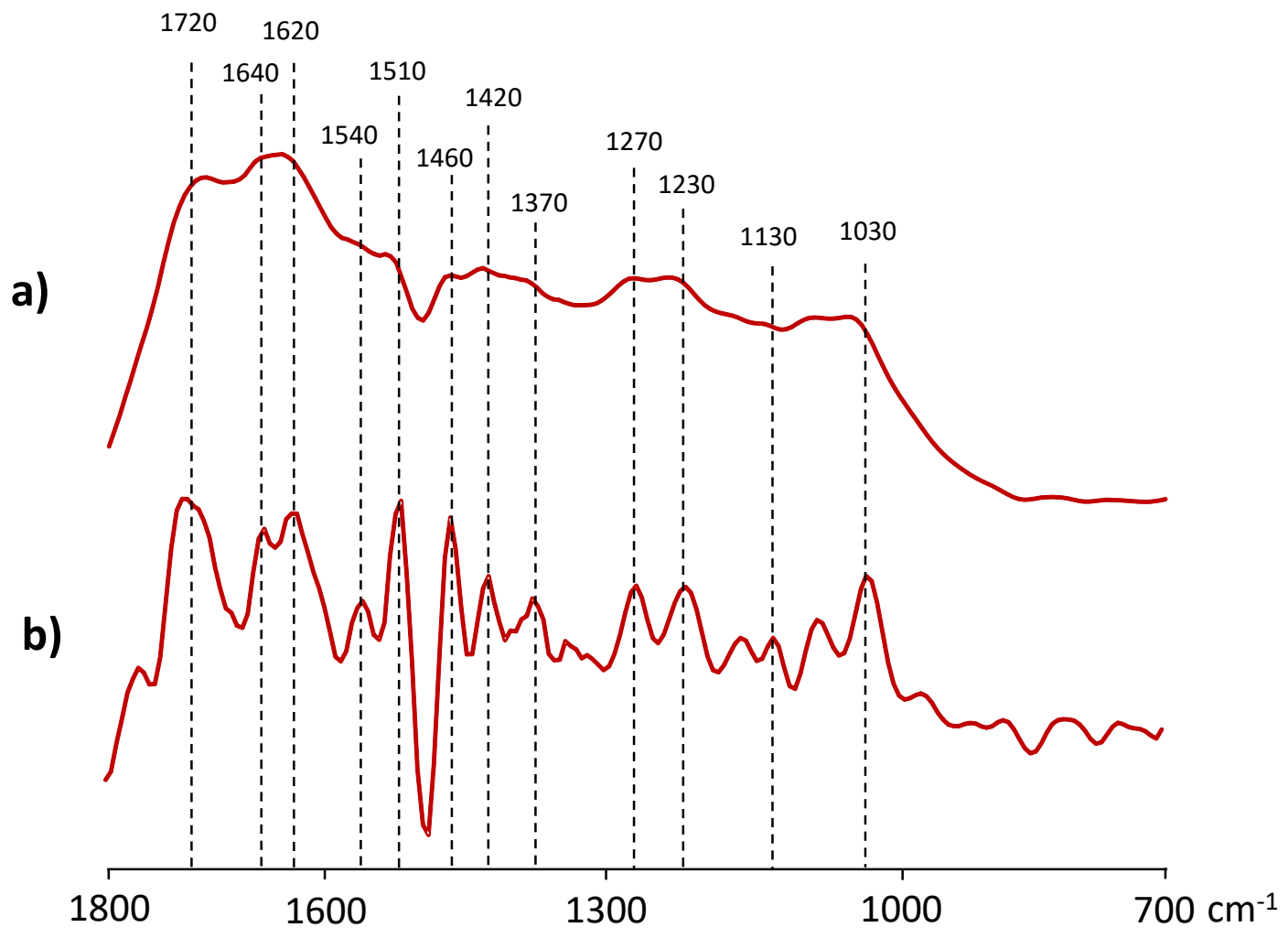

Figure 1. Infrared spectrum of sample 34 (a) compared with the corresponding resolution enhanced spectrum (b). 



Figure 2. Observed versus predicted values of soil organic carbon (SOC) and optical density at $465 \mathrm{~nm}$ of soil humic acids (E4) from Mediterranean soils calculated by partial least squares regression. Inner (orange) and outer (black) lines indicate 95\% confidence and prediction limits, respectively. 


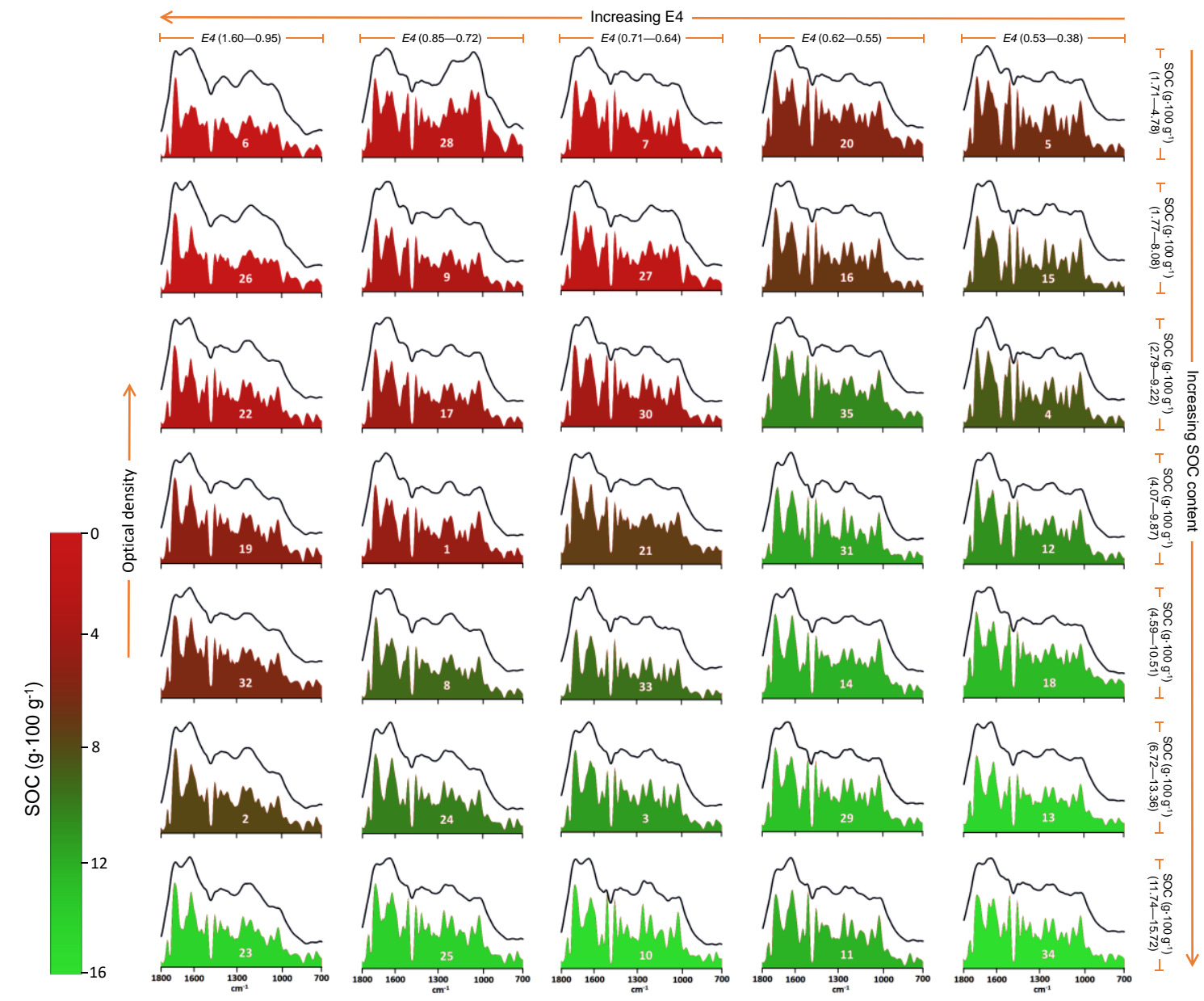

Figure 3. Representation of infrared spectra and resolution enhanced spectra of humic acids from Mediterranean soils. Samples are ordered horizontally in function of E4 value and vertically in function of increasing content of SOC. The samples are colored according the SOC content. Numbers of the spectra refer to Table 1. 


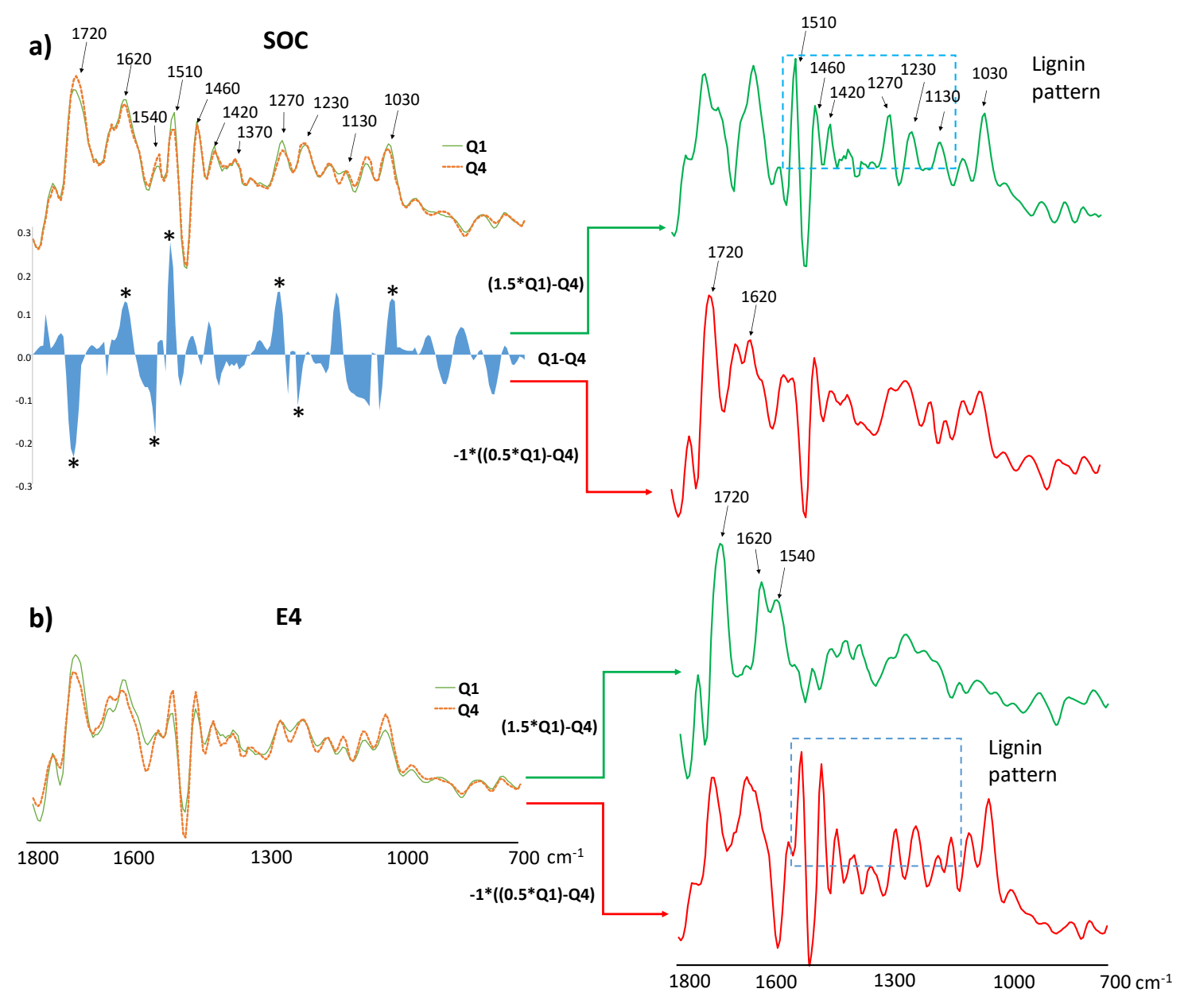

Figure 4. Comparison of IR patterns of humic acids (HA) in terms of a) soil organic carbon (SOC) levels and b) optical density at $465 \mathrm{~nm}$ of soil HA (E4). The subtraction values of spectral intensities between average IR spectra from HAs in extreme quartiles of the $S O C$ distribution in the corresponding soils is represented in a). The Q1-Q4 positive values correspond to bands predominating in C-rich soils, whereas negative values correspond to bands predominating in C-depleted soils. The asterisks $\left(^{*}\right)$ show values statistically different $(P<0.05)$ between band intensities of the IR spectrum in the soils with comparatively high $C$ storage potential as regards soils comparatively poor in C (Q1 and Q4) according to the Student's $t$ test. For a more perceptual spectroscopic interpretation of the organic constituents prevailing in each of the HAs from Q1 and Q4 soil sets, two independent spectra were calculated after zero-correction baseline by multiplying by a linear factor, showing the different composition of the corresponding HAs from samples of high (green trace) and low (red trace) values of the dependent variables $\mathrm{SOC}$ and $\mathrm{E} 4$, respectively. 


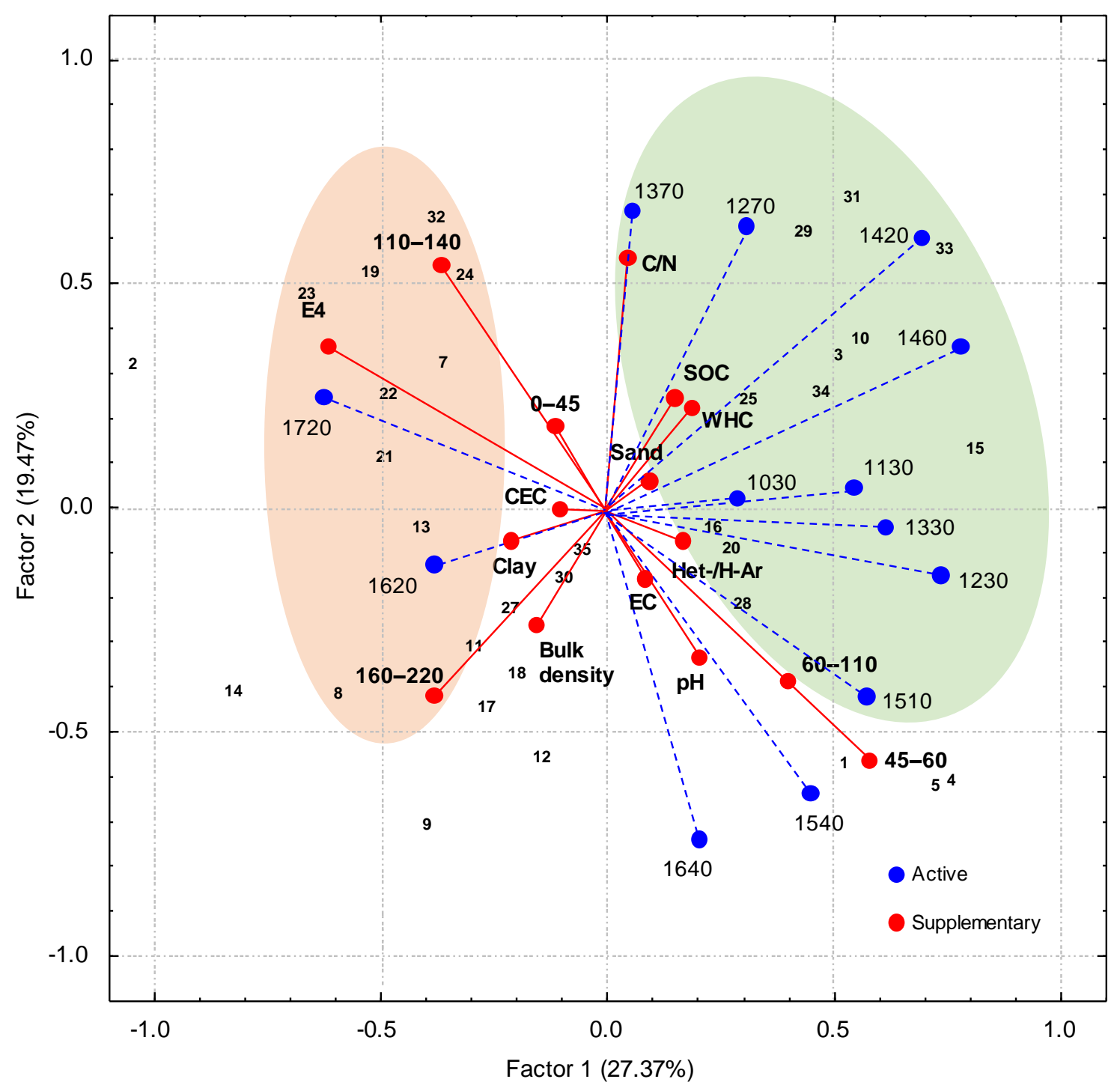

Figure 5. Biplot obtained by principal component analysis, with numbers (1-35) representing soil samples and eigenvectors pointing to the direction of increasing values of the independent variables (IR bands, represented with blue dashed lines). A series of soil properties (also considered as dependent variables and processed as supplementary variables) are displayed with solid red lines. The biplot suggest two main clusters with variables correlated with the SOC content (encircled in green) or the aromaticity of the HA (encircled in red), respectively. Variable labels refer to Table 1. Numbers refer to peak wavenumbers in the IR spectra $(1720,1640,1620$, $1540,1510,1460,1420,1370,1330,1270,1230,1130$ and $\left.1030 \mathrm{~cm}^{-1}\right)$ and signal area in selected ranges of the ${ }^{13} \mathrm{C}$ NMR spectra $(0-45,45-60,60-110,110-140$ and 160-220 ppm). 


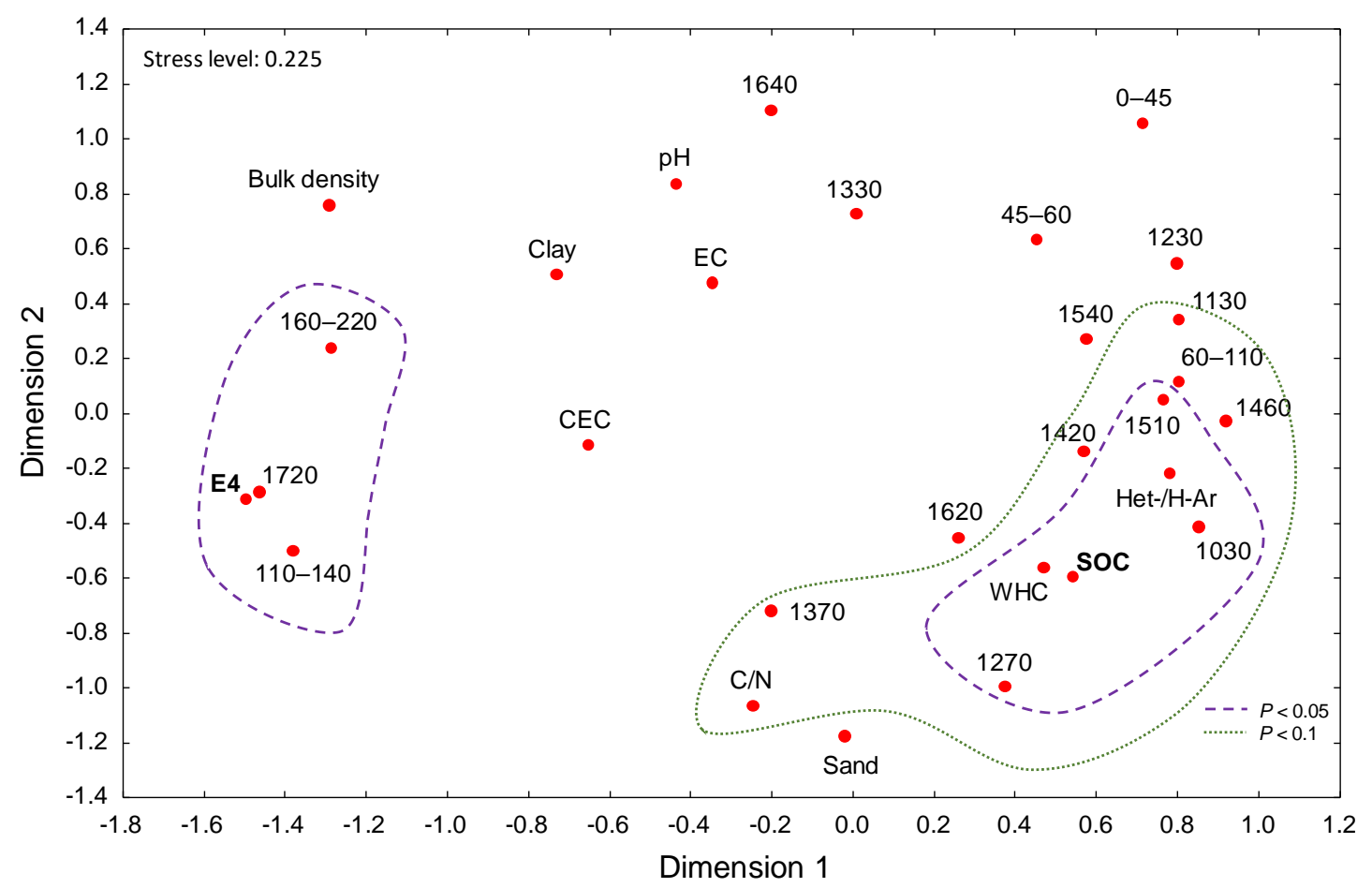

Figure 6. Representation, using multidimensional scaling (MDS) of the relationships between different soil properties and quality descriptors of SOM, and the intensities of the main bands of the IR spectra of the corresponding soil HAs. Concentric lines indicate the variables positively correlated either with the SOC content or with the E4 at $P<0.05$ (dashed line) and at $P<0.1$ (dotted line). Variable labels refer to Table 1. Numbers refer to peak intensities of the IR spectra $(1720,1640,1620,1540,1510$, $1460,1420,1370,1330,1270,1230,1130$ and $\left.1030 \mathrm{~cm}^{-1}\right)$ and signal area in selected ranges of the ${ }^{13} \mathrm{C}$ NMR spectra $(0-45,45-60,60-110,110-140$ and $160-$ $220 \mathrm{ppm})$. 